\title{
Evaluation of Omalizumab From a Health Plan Perspective
}

PAUL P. BELLIVEAU, PharmD, and MONINA R. LAHOZ, PhD

\begin{abstract}
OBJECTIVE: To review the pathophysiology of allergic asthma and information on the pharmacology, clinical efficacy, safety profile, and direct drug costs for omalizumab to provide a basis for a defined role of this agent in allergic asthma therapy in managed care organizations.

SUMMARY: Omalizumab is a monoclonal antibody targeting the high-affinity receptor binding site on human immunoglobulin $\mathrm{E}(\mathrm{lgE})$. When bound by omalizum$a b$, IgE does not bind to basophils. As a result, degranulation is attenuated and allergic asthma symptoms are reduced. In asthma trials, omalizumab reduced inhaled corticosteroid and rescue medication requirements and improved asthma control and asthma quality of life in moderate-to-severe allergic asthmatics with disease poorly controlled by inhaled corticosteroids. Omalizumab has generally been well tolerated. However, injection site reactions occur in nearly 1 of every 2 patients, a problem that generally becomes less with continued dose administration. Severe injection site reactions are reported in $12 \%$ of patients. Other adverse events commonly reported in clinical trials include viral infections $(23 \%)$, upper respiratory infections $(20 \%)$, sinusitis $(16 \%)$, headache $(15 \%)$, and pharyngitis $(11 \%)$. Because the acquisition cost of omalizumab is high (generally $\$ 15,000$ to $\$ 44,000$ per patient per year, before contractual discounts), its use is cost-prohibitive in all but the most severe, poorly controlled allergic asthmatic patients who are utilizing large amounts of emergency health care resources to manage exacerbations. Experience with use of this drug beyond 52 weeks is lacking.

CONCLUSION: Although omalizumab has demonstrated efficacy and safety in adults and adolescents with uncontrolled moderate-to-severe allergic asthma, its use should be restricted to a narrowly defined population of allergic asthmatics who utilize large amounts of health care resources. If targeted only toward this population, cost-of-care studies suggest that the high cost of this product in these patients could be offset by savings resulting from the less frequent use of high-intensity medical services for asthma exacerbations. The use of omalizumab beyond 52 weeks needs evaluation.
\end{abstract}

KEYWORDS: Omalizumab, RhuMab-E25, Anti-IgE, Allergic asthma

J Manag Care Pharm. 2005;11(9):735-45

Note: An editorial on the subject of this article appears on pages 774-76 of this issue.

\section{Authors}

PAUL P. BELLIVEAU, PharmD, is an associate professor, Department of Pharmacy Practice, and MONINA R. LAHOZ, PhD, is an associate professor, Department of Pharmaceutical Sciences, Massachusetts College of Pharmacy and Health Sciences, Worcester.

AUTHOR CORRESPONDENCE: Paul P. Belliveau, PharmD, Associate Professor, Department of Pharmacy Practice, Massachusetts College of Pharmacy and Health Sciences, 19 Foster St., Worcester, MA 01608. Tel: (508) 373-5655; Fax: (508) 756-8715; E-mail: paul.belliveau@wormcphs.edu

Copyright $\odot$ 2005, Academy of Managed Care Pharmacy. All rights reserved.
A sthma is a condition that has a significant societal impact. It affects a substantial population of patients and imposes a burden in terms of treatment costs, productivity loss, and reduced quality of life..$^{1-3}$ Although many medications are available for treatment of asthma, some focus only on symptom relief, others are nonspecific in their mechanism of action (and therefore produce substantial side effects), and none provides relief in all patients. ${ }^{4.5}$ Hence, there is a clear need for new interventions to improve the care of asthma patients. ${ }^{6}$

Omalizumab (Xolair), a monoclonal anti-immunoglobulin E (IgE) antibody, provides clinicians with an additional option for treating allergy-induced asthma. This review will provide a cost analysis of omalizumab to assist health plans in their decisions regarding the utility of this drug in select patient populations. Additionally, to provide the reader with a better understanding of the potential role for this product, the pathophysiology of allergic asthma will be reviewed, and relevant information on the pharmacology, clinical efficacy, and safety profile for omalizumab will be presented.

\section{Pathophysiology of Allergic Asthma}

Although not all cases of asthma are clearly attributable to atopy (the genetic tendency to develop the allergic diseases), it is accepted that atopy can play an etiologic role in its pathophysiology. Researchers who have reviewed this literature to calculate the weighted mean-population-attributable risk suggest that approximately $40 \%$ of asthma cases can be attributed to atopy. ${ }^{7}$ Additionally, atopy is one of the strongest predisposing factors for the development of asthma. ${ }^{4,8}$

Discussion of the pathophysiology of allergic asthma begins with exposure of an allergen to antigen-presenting cells (macrophages, dendritic cells) that engulf the allergen, process it, and display the peptide epitope of the allergen on its cell surface for presentation to $\mathrm{T}$ and $\mathrm{B}$ lymphocytes. This is followed by direct interactions between $\mathrm{T}$ and $\mathrm{B}$ lymphocytes, which initiate B lymphocyte activation and subsequent allergen-specific IgE production (Figure 1). ${ }^{9}$

IgE binds to high-affinity receptors (FcERI) on basophils and mast cells (basophil-like cells located in tissues). ${ }^{10,11}$ During subsequent antigen exposure, the antigen forms a link with multiple FceRI-bound IgE molecules on basophils. This triggers degranulation of these cells, resulting in the release of preformed inflammatory mediators (histamine, tryptase) and the synthesis and release of newly generated mediators (prostaglandins, leukotrienes) and cytokines (tumor necrosis factor [TNF], interleukin [IL]-4, IL-5, IL-6). Released mediators initiate an early-phase response within minutes after allergen exposure. In the bronchial mucosa, this manifests as an asthma exacerbation 


\section{FIGURE 1 Pathophysiology of Allergic Asthma} and the Action of Omalizumab

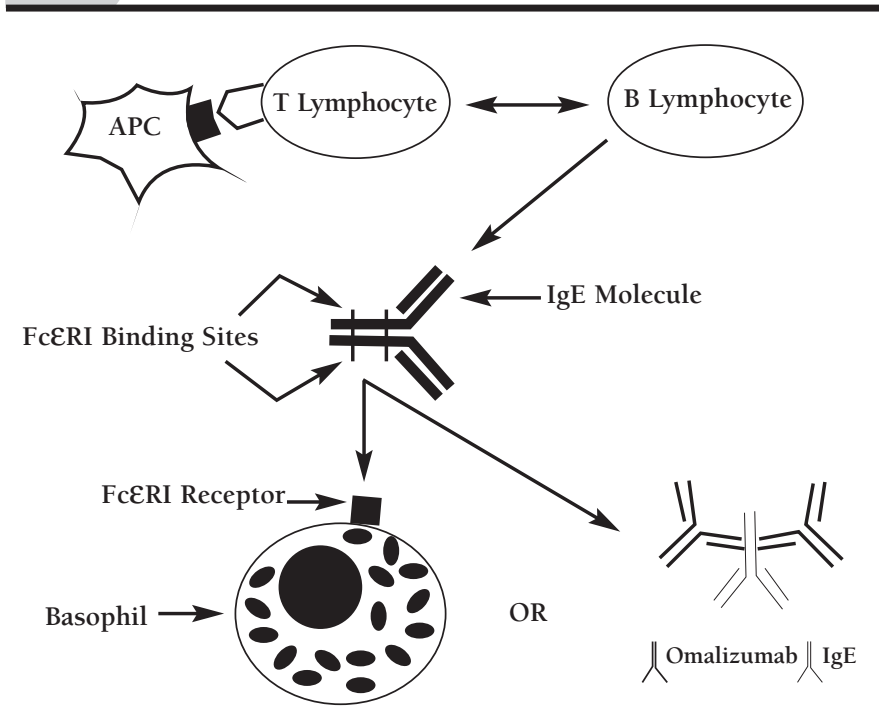

Note: After allergen exposure, the antigen-presenting cells (APC) process the antigen for presentation to the $T$ lymphocyte, prompting interactions between $T$ lymphocytes and B lymphocytes that result in immunoglobulin $\mathrm{E}$ (IgE) production. IgE may bind to the FcERI receptor on a basophil. With subsequent allergen exposure, the allergen will be bound by IgE on the basophil, resulting in release of inflammatory mediators and an allergic-asthma exacerbation. Omalizumab prevents the exacerbation by binding to IgE before it can bind to the basophil.

(mucosal edema, mucous production, bronchial smooth muscle spasm). ${ }^{4,12-14}$ Some mediators released during the acute-phase response act as chemoattractants and promote the infiltration of mucosal surfaces with eosinophils. ${ }^{13,15}$ With subsequent release of eosinophil and newly generated basophil products, a second wave of allergic symptoms can be observed over the 6 to 12 hours following the early-phase response.

\section{Omalizumab Pharmacology}

Omalizumab is a monoclonal antihuman $\operatorname{IgE}$ antibody. Omalizumab binds free human IgE with a binding affinity higher than that observed between IgE and FceRI (Figure 1) ) $^{1,17}$; it does not bind to basophils or to IgE that is already bound to FceRI. ${ }^{9,17,18}$ These binding characteristics allow omalizumab to neutralize IgE-mediated responses without causing basophil degranulation that could occur if omalizumab bound to basophils or if omalizumab cross-linked with basophil-bound IgE. ${ }^{19}$ Omalizumab also promotes FceRI down-regulation on basophils because of the close direct correlation between free serum IgE and the number of FceRIs expressed on basophils. ${ }^{20-22}$ As a result of these actions, the amount of basophil-bound IgE is reduced.

\section{Clinical Efficacy Trials}

Omalizumab has been evaluated in randomized, placebocontrolled, double-blinded clinical trials involving adolescents and adults with moderate-to-severe persistent allergic asthma (Table 1).23-26 Two of these trials were identically structured. Omalizumab doses were administered subcutaneously and standardized so that patients received an approximate dose of at least $0.016 \mathrm{mg} / \mathrm{kg}$ per IU of $\mathrm{IgE} / \mathrm{mL}$ every 4 weeks. Smaller doses of $150 \mathrm{mg}$ or $300 \mathrm{mg}$ were administered every 4 weeks; with larger monthly requirements, $225 \mathrm{mg}, 300 \mathrm{mg}$, or $375 \mathrm{mg}$ doses were administered every 2 weeks. Prior to enrollment, all inhaled steroid doses were converted to inhaled beclomethasone dipropionate (BDP) titrated to previous asthma control. In addition to the inclusion criteria listed in Table 1, patients needed to have residual asthma symptoms during the 2 weeks prior to randomization despite treatment with moderate-dose or high-dose inhaled corticosteroids (ICSs). Patients received 16 weeks of placebo or omalizumab in addition to their ICS therapy (steroid-stable phase). Therapies were then continued for another 12 weeks while ICS therapy was tapered (steroidreduction phase).

These studies enrolled 1,071 patients; the average baseline forced-expiratory-volume-in-1-second $\left(\mathrm{FEV}_{1}\right)$ measurement was approximately $70 \%$ of what was predicted..$^{23,24}$ There was a significant reduction in exacerbation frequency among omalizumab recipients during the steroid-stable and steroid-reduction phases of both trials when compared with placebo recipients (Table 1). Among the secondary end points, statistically significant differences were observed in favor of omalizumab treatment with regard to asthma symptom scores, beta-agonist rescue therapy use at most weekly intervals, $\mathrm{FEV}_{1}$ measurements at most weekly intervals, and the number of patients experiencing an exacerbation. These differences were observed despite more successful ICS tapering among omalizumab recipients, with patients being maintained on lower ICS doses or without any ICS requirements. These differences persisted in a 24-week double-blind extension phase in which patients continued their study treatment and the lowest effective BDP dose..$^{27,28}$

In 2 other trials, study inclusion criteria stipulated that only patients with baseline high-dose ICS requirements be enrolled, thus capturing a sample of patients considered to have severe persistent allergic asthma (based on the fact that they required high-dose ICS for symptom control. ${ }^{25,26}$ ) In a clinical trial structured similarly to those above (except that patients were converted to inhaled fluticasone at doses that provided disease control, the steroid-reduction phase was 16 weeks, and the primary end point was the percentage reduction in the fluticasone dose needed to maintain disease control), Holgate et al. enrolled 246 adult-adolescents with severe persistent allergic asthma (mean baseline $\mathrm{FEV}_{1}$ of $62.9 \%$ and $66 \%$ for omalizumab and placebo recipients, respectively). ${ }^{25}$ Although the number of exacerbation episodes per patient was similar in the omalizumab and placebo 
Evaluation of Omalizumab From a Health Plan Perspective

\section{TABLE 1$)$ Design and Primary Outcome Parameters for Omalizumab Clinical Studies}

\begin{tabular}{|c|c|c|c|c|c|}
\hline Study Citation & Design & Inclusion & Patients* & Principal Outcomes $\dagger$ & Comment/Other Results \\
\hline Soler et al. ${ }^{23}$ & $\begin{array}{l}\mathrm{R}, \mathrm{P}, \mathrm{DB} \\
28 \text { weeks }\end{array}$ & $\begin{array}{l}\text { 12-75 YOA } \\
\text { IgE } 30-700 \mathrm{IU} / \mathrm{mL} \\
\text { FEV } 40-80 \% \\
+ \text { SPT (1 allergen) }\end{array}$ & $274 / 272$ & $\begin{array}{l}\text { Stable phase: } 0.28 \text { vs. } 0.66 \text { exacerbations } \\
\text { per patient }(P<0.001) ; 58 \% \text { reduction } \\
\text { Reduction phase: } 0.36 \text { vs. } 0.75 \text { exacerbations } \\
\text { per patient }(P<0.001) ; 52 \% \text { reduction }\end{array}$ & $\begin{array}{l}\text { Omalizumab: greater } \\
\% \text { reduction of ICS } \\
\text { doses }(P<0.001) ; \text { ICS } \\
\text { discontinued in } 43 \% \\
\text { (vs. } 19 \% \text { for placebo) }\end{array}$ \\
\hline Buhl et al. ${ }^{27}$ & $\begin{array}{l}\text { Extension of } \\
\text { Soler et al. } \\
24 \text { weeks }\end{array}$ & As for Soler et al. & $254 / 229$ & $\begin{array}{l}0.48 \text { vs. } 1.14 \text { exacerbations per } \\
\text { patient }(P<0.001) ; 58 \% \text { reduction }\end{array}$ & $\begin{array}{l}\text { Omalizumab: fewer } \\
\text { patients with an } \\
\text { exacerbation }(24 \% \\
\text { vs. } 40.6 \%, P<0.001)\end{array}$ \\
\hline Busse et al. ${ }^{24}$ & $\begin{array}{l}\mathrm{R}, \mathrm{P}, \mathrm{DB} \\
28 \text { weeks }\end{array}$ & $\begin{array}{l}\text { 12-75 YOA } \\
\text { IgE } 30-700 \mathrm{IU} / \mathrm{mL} \\
\text { FEV } 40-80 \% \\
+ \text { SPT (1 allergen) }\end{array}$ & $268 / 257$ & $\begin{array}{l}\text { Stable phase: } 0.28 \text { vs. } 0.54 \text { exacerbations } \\
\text { per patient }(P=0.006) ; 48 \% \text { reduction } \\
\text { Reduction phase: } 0.39 \text { vs. } 0.66 \text { exacerbation } \\
\text { per patient }(P<0.003) ; 41 \% \text { reduction }\end{array}$ & $\begin{array}{l}\text { Omalizumab: greater } \\
\% \text { reduction of ICS } \\
\text { doses }(75 \% \text { vs. } 50 \% \text {, } \\
P<0.001 \text { ); ICS } \\
\text { discontinued in } \\
39.6 \% \text { (vs. } 19.1 \% \text { for } \\
\text { placebo, } P<0.001 \text { ) }\end{array}$ \\
\hline Lanier et al. ${ }^{28}$ & $\begin{array}{l}\text { Extension of } \\
\text { Busse et al. } \\
24 \text { weeks }\end{array}$ & As for Busse et al. & $245 / 215$ & $\begin{array}{l}0.60 \text { vs. } 0.83 \text { exacerbations } \\
\text { per patient }(P=0.023) ; 28 \% \text { reduction }\end{array}$ & $\begin{array}{l}\text { Omalizumab: fewer } \\
\text { patients with an } \\
\text { exacerbation }(31.8 \% \\
\text { vs. } 42.8 \%, P=0.015)\end{array}$ \\
\hline Holgate et al. ${ }^{25}$ & $\begin{array}{l}\mathrm{R}, \mathrm{P}, \mathrm{DB} \\
32 \text { weeks }\end{array}$ & $\begin{array}{l}12-75 \text { YOA } \\
\text { IgE } 30-700 \mathrm{IU} / \mathrm{mL} \\
+ \text { SPT (1 allergen) }\end{array}$ & $126 / 120$ & $\begin{array}{l}57.2 \% \text { vs. } 43.3 \% \text { lower ICS dose } \\
\text { requirement at end of steroid-reduction phase } \\
(P=0.003)\end{array}$ & $\begin{array}{l}\text { Designed to } \\
\text { demonstrate that } \\
\text { omalizumab } \\
\text { allows ICS dose } \\
\text { reductions without } \\
\text { loss of disease control }\end{array}$ \\
\hline Humbert et al. ${ }^{26}$ & $\begin{array}{l}\mathrm{R}, \mathrm{P}, \mathrm{DB} \\
28 \text { weeks }\end{array}$ & $\begin{array}{l}\text { 12-75 YOA } \\
\text { IgE } 30-700 \mathrm{IU} / \mathrm{mL} \\
+ \text { SPT (1 allergen) } \\
\text { FEV } 40-80 \%\end{array}$ & $209 / 210$ & $\begin{array}{l}0.68 \text { vs. } 0.91 \text { exacerbations } \\
\text { per patient }(P=0.042) ; 25 \% \text { reduction }\end{array}$ & $\begin{array}{l}\text { Omalizumab: fewer } \\
\text { severe exacerbations, } \\
(0.24 \text { vs. } 0.48 \text { per } \\
\text { patient, } P=0.002) \text { and } \\
\text { fewer acute care visits } \\
(24 \% \text { vs. } 43 \%, P=0.038)\end{array}$ \\
\hline Ayres et al. ${ }^{29}$ & $\begin{array}{l}\mathrm{R}, \mathrm{O}, \mathrm{PG} \\
52 \text { weeks }\end{array}$ & $\begin{array}{l}12-75 \text { YOA } \\
\text { IgE 30-700 IU/mL } \\
+ \text { SPT ( } 2 \text { allergens) }\end{array}$ & $206 / 106$ & $\begin{array}{l}\text { Omalizumab recipients experienced } 4.84 \\
\text { fewer ADRIs/patient year; } 49.6 \% \text { ( } 95 \% \\
\text { CI: 27.8-64.8\%) reduction compared with BSC }\end{array}$ & $\begin{array}{l}\text { Omalizumab: more } \\
\text { patients ADRI-free } \\
(36.1 \% \text { vs. } 20.2 \%) ; \\
\text { fewer with multiple } \\
\text { ADRIs ( } 40.8 \% \text { vs. } 66.3 \% \text {, } \\
P=0.001 \text { ) }\end{array}$ \\
\hline
\end{tabular}

* Omalizumab recipients/placebo recipients.

$\dagger$ Results of omalizumab recipients versus results of placebo recipients (or best standard care for Ayres et al.); stable refers to steroid-stable phase, and reduction refers to the steroid-reduction phase of the trials.

$A D R I S=$ asthma-related deterioration incidents; $B S C=$ best standard care; $D B=$ double-blind; FEV $1=$ forced expiratory volume in 1 second; ICS=inhaled corticosteroid; $O=$ open-label; $P=$ placebo-controlled; $P G=$ parallel group; $R=$ randomized; $S P T=$ skin-prick test; $Y O A=$ years of age.

groups, there was a greater reduction in fluticasone requirements and rescue medication use for omalizumab recipients (Table 1). Asthma symptom scores among omalizumab recipients were either lower or no different than those of placebo recipients at each assessment point.

In the most recently published trial, Humbert et al. evaluated 419 patients with severe persistent allergic asthma (mean baseline $\mathrm{FEV}_{1} 61 \%$ and $61.6 \%$ for omalizumab and placebo recipients, respectively), continuing asthma symptoms despite high-dose
ICS, and a history of 2 exacerbations requiring systemic steroids or 1 exacerbation requiring hospitalization/emergency department (ED) care over the year prior to enrollment. ${ }^{26}$ When added to the patient's baseline asthma therapy (attempts to taper inhaled ICS were not driven by study protocol) for 28 weeks, the asthma exacerbation rate was significantly lower among omalizumab recipients (Table 1). Among secondary parameters evaluated, omalizumab recipients had statistically significant greater improvements (versus placebo) in their morning peak expiratory 
flow (PEF) readings, $\mathrm{FEV}_{1}$ measurements, and asthma symptom scores. Additionally, omalizumab recipients experienced a significantly lower rate of severe exacerbations (PEF $<60 \%$ of personal best, requiring systemic corticosteroids) and total acute care visit requirements (doctor visits, ED care, hospitalization). Based on their findings, the investigators reported that 3 patients needed to be treated for 1 year with omalizumab to avoid 1 severe exacerbation.

To better evaluate omalizumab utility in real-life clinical practice, Ayres et al., in a multicenter, open-labeled study, randomized 312 poorly controlled (defined as at least 1 ED visit or hospitalization or at least 1 course of oral corticosteroids for asthma over the prior year) adult and adolescent patients with moderate-to-severe persistent allergic asthma, to best standard care (BSC) plus omalizumab or BSC only. ${ }^{29}$ The model for BSC was the guideline published by the National Heart, Lung, and Blood Institute. ${ }^{30}$ Over 12 months, omalizumab recipients experienced fewer asthma-deterioration-related incidents per patient day (ADRIs, defined as 2 or more lost work/school days, the need for an unscheduled physician or hospitalization/ ED visit, or the need for treatment with systemic corticosteroids or antibiotics due to asthma) (Table 1). Additionally, more omalizumab recipients remained ADRI-free and fewer experienced multiple ADRIs. There were also differences in types of ADRIs, with a smaller percentage of omalizumab recipients requiring systemic corticosteroids (51.8\% vs. $65.2 \%, P=0.037)$, an unscheduled physician visit ( $33.5 \%$ vs. $50.6 \%, P=0.007)$, or $>2$ days time off from work or school $(43.5 \%$ vs. $57.3 \%, P=0.031)$. Statistically significant differences in favor of omalizumab were observed in the measurements of rescue medication use, morning $\mathrm{FEV}_{1}$ measurements, asthma symptoms scores, and mean daily ICS requirements.

\section{Asthma-Related Quality of Life and Perceptions of Treatment Efficacy}

Because conventional clinical measures of asthma are not complete descriptions of the functional impairments or improvements experienced in clinical trials, ${ }^{31}$ investigators also included measures of quality-of-life and treatment-efficacy perceptions. Quality of life was evaluated via a validated Asthma Quality of Life (AQoL) Questionnaire. ${ }^{32,33}$ Impressions of therapy effectiveness were evaluated by asking patients and investigators to rate treatment efficacy as excellent, good, moderate, poor, or worse.

In the trials reported by Soler et al. and Busse et al., overall AQoL scores among omalizumab recipients showed significantly greater improvement (relative to baseline) during all 3 treatment phases. Additionally, in each phase, a significantly greater proportion of patients experienced a clinically relevant change in their overall AQoL score; a significantly greater proportion also experienced a large improvement (quantitatively greater than a clinically relevant change). ${ }^{34,35}$ Similar improvements were reported in the trials evaluating patients with severe persistent allergic asthma. ${ }^{25,26}$

Patients' and investigators' impressions of therapy effectiveness were consistent with AQoL evaluations, lending validity to this simple assessment method. With assessments performed at the end of the steroid-reduction phases, ratings by patients and investigators were more likely to be good or excellent for the omalizumab recipients. The percentage of patients indicating that response was good or excellent among omalizumab and placebo recipients, respectively, was: Soler et al., 70\% versus $40 \%, P<0.001^{34}$; Busse et al., $60.6 \%$ versus $38.1 \%, P<0.001^{24,35}$; Humbert et al., $64.3 \%$ versus $43.3 \%, P<0.001 .{ }^{26}$ Investigator responses were similar to those of patients.

\section{Secondary Analyses of Clinical Trial Data}

Bousquet and colleagues pooled data from 7 adult/adolescent trials of allergic asthma (5 discussed in this text, ${ }^{23-29} 1$ not included here because it enrolled patients with concomitant allergic asthma and perennial allergic rhinitis, and 1 currently unpublished) to assess the effect of omalizumab treatment on exacerbations in patients with severe persistent allergic asthma. ${ }^{36}$ Asthma severity was based on the Global Initiative for Asthma guidelines, which categorize severity based on clinical features and the intensity of the therapy required for symptom control. ${ }^{37}$ This pooled analysis of 4,308 patients showed a lower rate of exacerbations for omalizumab recipients ( 0.91 vs. 1.47 exacerbations per year, $P<0.001 ; 38 \%$ reduction). Additionally, omalizumab recipients had rates of hospitalization that were $52 \%$ lower $(P=0.041)$, ED visits that were $61 \%$ lower $(P=0.013)$, and unscheduled doctor visits that were $43 \%$ lower $(P<0.001)$. Although the number needed to treat is not reported by the investigators, there are sufficient data to calculate such values. Approximately 6 patients would have to be treated for 1 year to avoid 1 unscheduled doctor visit, 25 would have to be treated for 1 year to avoid 1 ED visit, and 32 would have to be treated for 1 year to avoid 1 hospital admission.

In another publication, Bousquet and colleagues pooled data from 2 of the adult/adolescent clinical trials of allergic asthma to identify the baseline patient characteristics that are predictive of response to omalizumab. ${ }^{38}$ Logistic regression analysis of the data from the steroid-stable phase of these trials revealed that the following characteristics were predictive of response: a history of emergency asthma treatment in the prior year, a baseline requirement for high doses ( $>800 \mathrm{mcg} / \mathrm{d})$ of inhaled BDP, and a baseline $\mathrm{FEV}_{1}$ of $<65 \%$ of predicted (odds ratio for response with all 3 factors present was 4.20, 95\% CI: 1.69-10.45). Baseline IgE concentrations were not predictive of response. Among patients showing a response to omalizumab at 16 weeks (the end of the steroid-stable phase), 61\% had responded by 4 weeks, and $87 \%$ had responded by 12 weeks of therapy.

With the data from the steroid-stable phases of 3 adultadolescent trials of allergic asthma, ${ }^{23-25}$ Holgate et al. performed 
a meta-analysis to evaluate the impact of omalizumab on an annualized rate of all asthma exacerbation episodes (AEEs) and significant AEEs (sAEEs, an exacerbation requiring doubling of the ICS dose or use of systemic steroids) among patients who were at high risk of serious asthma-related morbidity and mortality. ${ }^{39}$ The investigators defined this population as those patients who had ever been intubated or who, within the year prior to enrollment, had visited an ED, required an overnight hospitalization, or needed intensive care unit admission for an asthma exacerbation. The rate of AEEs and sAEEs was lower with omalizumab treatment relative to placebo (rates were 53\% and 55\% lower, respectively; $P$ values $<0.001$ ). The absolute difference (in favor of omalizumab) in sAEE rates increased dramatically with baseline $\mathrm{FEV}_{1}$ severity. Differences in the risk of sAEEs translated into the need to treat 5 patients with omalizumab to maintain 1 patient free of sAEEs for the period of study (average of 41.7 weeks for the 3 studies).

\section{Safety and Tolerability}

In the omalizumab package insert, the descriptions of reported adverse events and those considered to be drug related in allergic asthma trials indicate that such events have occurred with similar frequency in omalizumab and placebo (injection) recipients. Most reactions were mild to moderate in severity. ${ }^{40}$ The most commonly reported adverse events with omalizumab therapy were injection-site reactions (45\%), viral infections (23\%), upper respiratory infections (20\%), sinusitis (16\%), headache (15\%), and pharyngitis (11\%). Injection-site reactions of any severity occurred in $45 \%$ of omalizumab recipients and $43 \%$ of placebo recipients. Reactions included bruising, redness, warmth, burning, stinging, itching, hive formation, pain, induration, mass formation, and inflammation. Most of these reactions occurred within 1 hour of injection, resolved within 8 days, and generally decreased in frequency with subsequent dosing. Severe injection-site reactions were reported in 12\% of omalizumab and $9 \%$ of placebo recipients. The package insert provides neither a description of "severe injection-site reaction" nor data on the percentage of patients who stopped therapy due to such reactions.

Although 1 group of investigators has reported a greater frequency of headache $(17.5 \%$ vs. $5.7 \%)$, cough $(7.8 \%$ vs. $1.9 \%$ ), and nausea ( $6.8 \%$ vs. $0.9 \%$ ) with omalizumab therapy, ${ }^{29}$ in the published reports of the adult-adolescent allergic asthma trials, there was typically little difference between omalizumab and placebo recipients with regard to adverse-event reporting. The types of events reported are consistent with the product package insert. ${ }^{23-29}$ Local injection-site reactions were associated with $8.6 \%$ to $20.4 \%$ of omalizumab injections and $6.5 \%$ to $10.3 \%$ of placebo injections. ${ }^{23-25,27}$ In the trial by Soler et al., bruising was the most common reaction reported by both omalizumab and placebo recipients; redness, warmth, and itching were more common among omalizumab recipients. ${ }^{23}$
In studies that include descriptions of laboratory monitoring with omalizumab treatment, clinically significant changes in such values have not been observed. ${ }^{24,26,28,29}$ Although early animal studies raised concerns about omalizumab-induced thrombocytopenia ${ }^{41}$ the product manufacturer reports that clinical trials have not revealed cases of sustained thrombocytopenia in patients with normal baseline platelet counts (data on file, Genentech, Inc.). Additionally, in a recent report of an openlabeled safety trial of 864 patients with moderate-to-severe asthma, platelet counts of $<100,000 / \mathrm{mm} 3$ occurred in $4.8 \%$ of omalizumab recipients and $5.7 \%$ of control patients (standard therapy group); a $50 \%$ drop was observed in $0.86 \%$ and $0.71 \%$, respectively.2 None of the patients had platelet counts of $<75,000 / \mathrm{mm} 3$, all reductions were isolated and transient, and there were no reports of bleeding. Despite the early concerns with thrombocytopenia, there are no warnings, black-box messages, or contraindications in the product package insert that suggest that baseline platelet counts must be evaluated prior to initiating therapy with omalizumab.

According to the product package insert, anaphylaxis was reported in 3 patients (incidence of $<0.1 \%$ ). These reactions occurred within 2 hours of a first or subsequent omalizumab dose. Symptoms included urticaria and throat and/or tongue edema. Respiratory failure was not observed, and all patients survived..$^{40}$ Although urticaria is described in patients involved in the discussed clinical trials, it was not described as a common adverse event. ${ }^{23,24,26}$ These reactions were typically mild or moderate in severity and usually resolved quickly with therapy discontinuation or despite continued therapy; the incidence of urticaria has been similar in omalizumab and placebo recipients.

In clinical trials of omalizumab, several investigators included analysis of the development of antiomalizumab antibodies. Such antibodies were not detected in any of these trials. ${ }^{23,24,27,28}$ In the product package insert, it is reported that low titers of antiomalizumab antibodies have been detected in 1 of 1,723 treated patients. ${ }^{40}$ Although omalizumab administration results in immune complex formation, investigators have not observed evidence of reactions that would be considered manifestations of complex precipitation or complement activation..$^{27,28}$

Among the warnings in the product package insert is mention of malignant neoplasms. ${ }^{40}$ Malignancies were observed in 20 of $4,127(0.5 \%)$ omalizumab recipients and 5 of 2,236 (0.2\%) placebo recipients involved in clinical studies. In 18 of these patients, the events occurred within 12 months of therapy initiation; approximately $60 \%$ were within 6 months. Several patients had a history of cancers, premalignant conditions, or other risk factors for development of a malignancy. Although it is hypothesized that the immune systems of atopic persons may be better able to identify and reject clones of malignant cells, a link between IgE and cancer has not been established. ${ }^{43,44}$ Nevertheless, since the majority of patients in clinical trials have had no more than a year's exposure to omalizumab, the risk for 


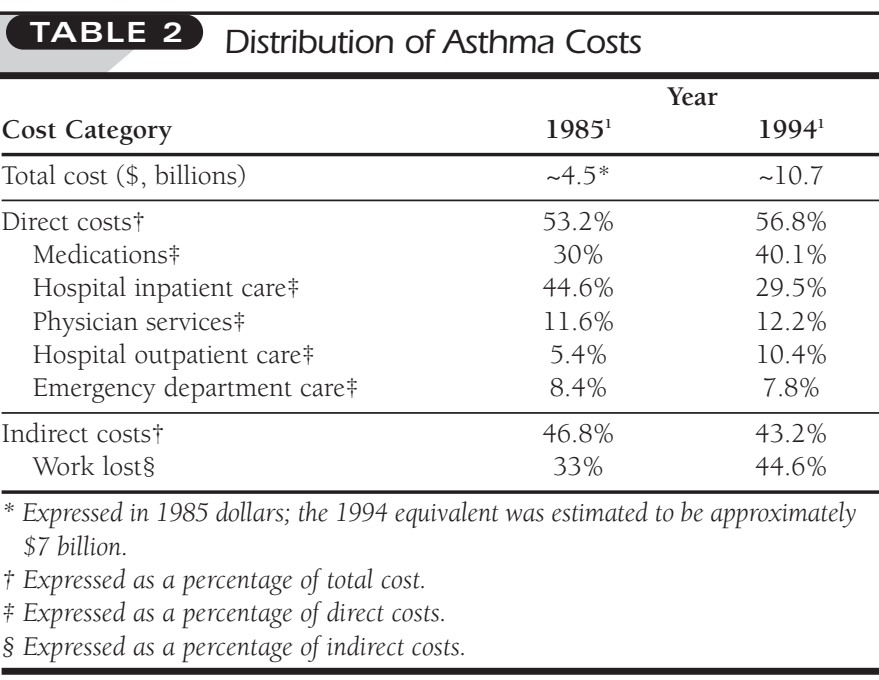

malignancy with more prolonged treatment needs to be studied, particularly in individuals who may be at higher risk for malignancies.

\section{Cost Analysis}

\section{Asthma Prevalence and Severity}

In the 2003 National Health Interview Survey of persons aged 18 years or older, an estimated 9.7\% (20.6 million) reported that they have been diagnosed with asthma during their lifetime and 6.4\% (13.6 million) reported that they still have asthma. ${ }^{45}$ Among children younger than 18 years, an estimated $12.5 \%$ (9 million) have had asthma diagnosed at some time in their lives, with the percentage increasing as age increases. ${ }^{46}$ Almost $6 \%$ of those surveyed (4 million) reported having had an asthma attack in the 12 months preceding the survey. Among U.S. high school students (grades 9 to 12) who participated in the 2003 National Youth Risk Behavior Survey, 18.9\% have been diagnosed with asthma at some time in their lives; $16.1 \%$ reported that they still had a diagnosis of asthma. ${ }^{47}$

The 1998 Asthma in America Survey reported that the percentage of patients reporting symptoms consistent with mild, moderate, and severe persistent asthma was 39.8\%, $22.1 \%$, and $19.1 \%$, respectively, ${ }^{48}$ and $19.1 \%$ reported symptoms consistent with mild intermittent disease. In a more recent survey of pediatric asthmatics, the percentage of parents reporting that their child had symptoms consistent with mild, moderate, and severe persistent asthma over the 4 weeks prior to the interview was $14 \%$ in each category. The remainder of the respondents (58\%) said their child had mild intermittent asthma. ${ }^{49}$

\section{Costs of Asthma}

Recent economic analyses indicate that direct medical costs, particularly hospitalizations and medications, currently account for the largest component of asthma-related costs in the United States. Using data from surveys conducted by the National Center for Health Statistics, Weiss and colleagues examined the changes in asthma costs during the 10-year period from 1985 through 1994. ${ }^{1}$ The total cost of asthma was $\$ 10.7$ billion in 1994, a figure that was more than twice the estimated cost of asthma (nearly $\$ 4.5$ billion) 10 years earlier in 1984 . This represented a 54.1\% increase after adjustment to 1994 dollars. Direct medical costs (including charges for hospital inpatient and outpatient services, ED services, physician services, and medications) amounted to $\$ 6.10$ billion in 1994 (56.8\% of the total costs), an increase of $22.6 \%$ during the 10 -year period. In 1985, hospital inpatient care represented the largest direct medical component cost (44.6\% of total direct costs). In 1994, the largest component cost of asthma was medications ( $\$ 2.45$ billion, $40.1 \%$ of total direct costs), followed by hospital inpatient care ( $\$ 1.80$ billion, $29.5 \%$ of total direct costs). The authors indicated that these observed trends were the result of a decrease in length of hospital stay (rather than a decrease in hospitalizations) and an increase in both the total number of prescribed medications and the average unit cost per medication. Indirect costs (including the value of time lost from school and work, and mortality as measured by lifetime earnings) of asthma in 1994 were estimated at $\$ 4.6$ billion (43.2\% of the total costs). The largest component of indirect cost in 1994 was loss of work, which was estimated at $\$ 2.07$ billion (44.6\% of indirect costs). Table 2 presents the distribution of asthma costs in 1985 and 1994.

Cisternas and colleagues conducted a comprehensive study of the direct and indirect costs of adult asthma using data derived from a group of community physicians treating 401 adult asthma sufferers in the northern California area. ${ }^{50}$ In this study, annual asthma costs averaged $\$ 4,912$ per person. Direct medical and nonmedical costs accounted for $64.8 \%$ of these costs. Fifty percent of direct total costs were ascribed to pharmaceuticals and only $14.6 \%$ to hospitalizations. Indirect costs (including wage losses associated with work disability and other productivity losses attributed to asthma disability in persons who did not work outside of home) accounted for 35.2\% of total costs. Almost all of the indirect costs were attributed to work/productivity losses.

\section{Asthma Severity and Health Care Resource Utilization}

In 2002, asthma accounted for 12.7 million doctor visits, 1.2 million hospital outpatient visits, 1.9 million ED visits, and 484,000 hospitalizations. Of these numbers, children aged 0 to 17 years had 5 million doctor visits, 727,000 ED visits, and 196,000 hospitalizations..$^{51}$ A disproportionate amount of these health care resources is utilized by a relatively small cohort of patients with difficult-to-treat asthma. ${ }^{52-54}$ Some investigators have reported that as much as $80 \%$ of direct asthma costs are consumed by less than 20\% of asthma patients (defined as 
TABLE 3 Annual Drug Cost for Omalizumab ${ }^{* \dagger}$

\begin{tabular}{lccc}
\hline Dose Regimen & $\begin{array}{c}\text { Vials } \\
\text { per Dose }\end{array}$ & $\begin{array}{c}\text { Injections } \\
\text { per Dose } \ddagger\end{array}$ & $\begin{array}{c}\text { Drug } \\
\text { Cost }(\$)\end{array}$ \\
\hline 150 mg every 4 weeks & 1 & 1 & 7,388 \\
200 mg every 4 weeks & 2 & 2 & 14,776 \\
225 mg every 2 weeks & 2 & 2 & 29,552 \\
300 mg every 2 weeks & 2 & 2 & 29,552 \\
375 mg every 2 weeks & 3 & 3 & 44,328 \\
\hline
\end{tabular}

* Based on average wholesale price (2005) of $\$ 568.31$ per $150 \mathrm{mg}$ in a $1.2 \mathrm{~mL}$ vial (from reference 58). Also available in a $0.6 \mathrm{~mL}, 75 \mathrm{mg}$ vial.

$\dagger$ Dose requirements for the majority of patients will likely be $>150 \mathrm{mg}$ every 4 weeks since this regimen is used only for patients who are $\leq 90 \mathrm{~kg}$ and have serum IgE levels at the lowest end of the range (30-100 IU/mL). In clinical trials of omalizumab, the mean serum IgE concentrations were 167-267 IU/mL. ${ }^{23-26,29}$ Therefore, an average omalizumab dose may be $300 \mathrm{mg}$ every 4 weeks or $225 \mathrm{mg}$ every 2 weeks, depending on the patient's body weight.

$\$ 150 \mathrm{mg}$ dose is delivered in a $1.2 \mathrm{~mL}$ volume. Because of the viscosity of the product, each injection should be no more than $1.2 \mathrm{~mL}$. Doses $>150 \mathrm{mg}$ need to be administered with separate injections. Omalizumab for subcutaneous administration is for single use only; any remaining unused product is discarded.

"high-cost patients"). ${ }^{55}$ The estimated annual cost per high-cost patient was $\$ 2,584$ compared with $\$ 140$ for other patients with asthma. ${ }^{55}$ As highlighted by the Epidemiology and Natural History of Asthma: Outcomes and Treatment Regimens (TENOR) study, these high-cost patients require a greater number of ED visits, hospitalizations, medications, and office/clinic visits. ${ }^{56}$

Cisternas and colleagues found significant differences in total per-person direct annual costs among asthma patients with varying self-reported severities of disease. The direct annual average costs (adjusted to 1998 dollars) for patients whose disease was categorized as mild, moderate, or severe were $\$ 2,646, \$ 4,530$, and $\$ 12,813$, respectively. ${ }^{50}$ Disease severity also had an impact on specific components of expenses. Hospital admissions comprised $4 \%, 5 \%$, and $17 \%$ of total direct annual costs, and medication costs comprised 47\%, 39\%, and $19 \%$ of total direct annual costs for persons with mild, moderate, and severe asthma, respectively. In a more recent investigation utilizing an independent expert panel of physicians to assess asthma severity, Godard et al. also reported significant differences in direct treatment costs of asthmatic patients, with greater costs being observed in patients with more severe disease. ${ }^{53}$

Improvements in the management of the most severe asthmatics could have a substantial impact on asthma care costs. Cisternas and colleagues concluded that a 5\% shift of patients from a severe to a moderate asthma classification would save approximately $\$ 1.4$ billion annually. ${ }^{50}$ As suggested by the inverse relationship between the direct costs of hospitalizations and medications reported by Cisternas and colleagues, adequately managed asthma is likely to reduce hospitalizations. ${ }^{50,57}$ With improved medication management, medication costs will likely increase, but the cost associated with hospitalization will likely decrease.

\section{Resource Use and Costs for Omalizumab Treatment: A Health Plan's Perspective \\ Drug Product Costs}

According to package insert dosing guidelines, omalizumab is administered only by subcutaneous injection. ${ }^{40}$ Doses are standardized so that patients receive an approximate dose of at least $0.016 \mathrm{mg} / \mathrm{kg}$ per IU of IgE/mL every 4 weeks. Smaller doses of $150 \mathrm{mg}$ or $300 \mathrm{mg}$ are administered every 4 weeks; with larger dose requirements ( $225 \mathrm{mg}, 300 \mathrm{mg}$, or $375 \mathrm{mg}$ every 4 weeks), doses are divided and administered every 2 weeks. Because of the viscosity of the product, doses greater than 150 mg must be administered as separate injections. The 2005 average wholesale price for one 150-mg single-dose vial of omalizumab is $\$ 568.31 .^{58}$ As shown in Table 3, the lowest dose regimen (one 150 -mg vial every 4 weeks) will cost $\$ 7,388$ per year ( $\$ 616$ per month), while the largest dose regimen (375 mg, or 3 vials, every 2 weeks) will cost $\$ 44,328$ per year ( $\$ 3,694$ per month). Dose requirements for the majority of patients will be likely be $>150 \mathrm{mg}$ every 4 weeks since this regimen is used only for patients who are $\leq 90 \mathrm{~kg}$ and have serum IgE levels at the lowest end of the range (30-100 IU/mL). In clinical trials of omalizumab, the mean serum IgE concentrations were 167-267 $\mathrm{IU} / \mathrm{mL} .^{23-26,29}$ Therefore, an average omalizumab dose may be 300 mg every 4 weeks or 225 mg every 2 weeks, depending on the patient's body weight.

\section{Drug Acquisition, Preparation, and Administration-related Costs}

Omalizumab distribution is restricted through a group of 5 specialty pharmacies, which can assist health care providers and patients with assessing insurance coverage and pursuing appropriate reimbursement authorization (i.e., obtaining prior approval). In order for specialty pharmacies to seek prior authorization from payers, the following information is requested: patient weight; International Classification of Diseases, Ninth Revision, (ICD-9) codes; current asthma therapies; documentation of a positive skin or radioallergosorbent test to a perennial aeroallergen; a statement of medical justification for omalizumab treatment; and a pretreatment IgE serum level (see http://www.xolair.com/hcp/hcp_home.jsp). Although the health care provider can obtain payer approval themselves, the drug would still need to be obtained through one of the specialty pharmacies. Under this circumstance, however, providers would need to forward prior authorization documentation to the specialty pharmacy or purchase the drug and bill the payer themselves. The drug may be shipped to the provider or directly to the patient. The time spent in this drug acquisition process is a factor to consider when the total cost of therapy is being evaluated. 


\section{TABLE 4 Ancillary Cost Considerations for Acquisition and Administration of Omalizumab}

1. Measuring a patient's serum total IgE (IU/mL) before the start of treatment.

2. Preparing paperwork necessary for drug acquisition.

3. Reconstituting/preparing the lyophilized product (for each $150 \mathrm{mg}$ vial): - 15 to 20 minutes; the vial has to be shaken for 5 tolo seconds approximately every 5 minutes to dissolve the solid particles; reconstituted product must be used within 4 to 8 hours, depending upon storage conditions

4. Injecting the product subcutaneously (no more than $150 \mathrm{mg}$ injected per site).*

5. Observing the patient after subcutaneous injection for 1 to 2 hours for possible severe hypersensitivity reactions including anaphylaxis:

- medications (e.g., diphenhydramine, hydroxyzine, epinephrine) for the treatment of severe hypersensitivity reactions.

6. Health care professional fees to perform the above tasks.

7. Patient and family costs associated with time and travel every 2 to 4 weeks.

* It's likely that a majority of patients will require doses $>150 \mathrm{mg}$ since the regimen of $150 \mathrm{mg}$ every 4 weeks is used only for patients who are $\leq 90 \mathrm{~kg}$ and have serum IgE levels at the lowest end of the range (30-100 IU/mL).

Doses and dosing frequency of omalizumab are based on patient weight and baseline serum IgE levels. ${ }^{40}$ Measuring a serum total IgE level (IU/mL) before the start of treatment adds to the total costs of therapy. Since the single-use product vials contain no preservatives, the solution must be administered within 4 to 8 hours of reconstitution, depending on storage conditions. This requires additional planning on the part of the provider. As the lypholized product takes approximately 15 to 20 minutes to dissolve, the patient must typically arrive at least 30 minutes before drug administration. Because of the product's cost, the patient's arrival is likely to be used as the trigger for the drug preparation and reconstitution process so as to prevent unnecessary waste. It is recommended that the patient also stay 1 to 2 hours after subcutaneous injection and be observed for possible severe hypersensitivity reactions, including anaphylaxis. Table 4 shows some of the ancillary cost considerations associated with omalizumab prescribing and administration.

Although providers may wish to coordinate injections for multiple patients to avoid drug waste, there is currently no literature describing such an effort. Additionally, this practice may be hampered by the intricate acquisition process, the short time window between reconstitution and injection, and the fact that many providers may not have a sufficient volume of patients receiving this product.

\section{Cost-effectiveness of Omalizumab}

Health care plans and pharmacy benefit managers will have to evaluate how and where omalizumab fits in drug formularies and policies regarding restricted access. Because of product cost, omalizumab will likely be placed in a "restricted use" category, where prior authorization is needed to dispense omalizumab to patients who meet specific criteria (Table 5).

With appropriate screening for those severe, high-cost asthma patients who are most likely to benefit, use of this product could result in a reduction in the cost of care for patients who utilize large amounts of resources, particularly those who require frequent hospitalizations, ED visits, and physician visits. To address this issue, a health plan would review the disease demographics of its enrollees. In particular, a health plan would need to know the number of asthmatics it serves and determine the distribution of disease severity of these enrollees. Additionally, it could review the amounts spent on the most severe, highest-cost allergic asthmatics who have incurred expenses perhaps because of poorly controlled disease. Expenditures for these patients would then be compared with what it would cost to pay for omalizumab in such patients. The plan could determine if the anticipated reduction in resource utilization (e.g., fewer hospital admissions, reductions in ED use and outpatient visits) of patients receiving omalizumab would sufficiently offset the costs associated with product acquisition, preparation, and administration, including the incurred costs from adverse events associated with drug administration.

Omalizumab was approved by the U.S. Food and Drug Administration in 2003, and from the outset there have been concerns regarding the cost-effectiveness of omalizumab because of its high acquisition cost. ${ }^{59,60}$ One economic analysis has shown that it may not be cost effective to administer omalizumab to any patient who is not a high-end asthma resource consumer. ${ }^{61}$ Oba and Salzman, utilizing a third-partypayer's perspective, performed a retrospective economic analysis to evaluate the cost-effectiveness of omalizumab. These investigators used the 52-week data from 2 of the previously discussed randomized clinical trials in adults and adolescents with moderate-to-severe allergic asthma. ${ }^{23,24,61}$ Direct costs were considered (including unscheduled physician office visits, hospitalizations, ED visits, treatment costs for drug-related adverse events, and asthma medication treatment costs). All costs were reported in 2003 dollars; at the time of analysis, the wholesale acquisition cost for omalizumab was $\$ 433$ for one $150 \mathrm{mg}$ vial. The authors estimated that the average daily treatment cost for patients treated with omalizumab was $\$ 39.85$ per patient compared with $\$ 2.08$ for patients receiving placebo injections, with the significant difference between the 2 treatments due primarily to drug product cost. The average daily cost associated with utilization of other health care resources was $\$ 0.08$ and $\$ 0.36$ per patient for the omalizumab and placebo recipients, respectively. The cost of gaining 1 additional successfully controlled day with the use of omalizumab was $\$ 523$. In the opinion of the authors, omalizumab use could result in cost savings only if used in the patient who is hospitalized at least 5 times or 20 days per year or requires at least 
Evaluation of Omalizumab From a Health Plan Perspective

TABLE 5 Proposed Criteria for Omalizumab Use

Criterion

Comment

Reference, Criteria Basis

Patients should fulfill all of the following:

High-risk* patient with

severe persistent asthma $\dagger$

Indicated for moderate-to-severe asthma but product

$23-29,36,38-40,61$

Age $>12$ years
Symptoms with appropriate therapy
after $1-2$ month trial
cost may dictate stricter criteria

Labeled indication 40

Appropriate maximal maintenance therapy for severe persistent asthma: high-dose ICS ( $>800 \mathrm{mcg} /$ day BDP, CFC or equivalent) plus LABA plus oral corticosteroid

\begin{tabular}{|c|c|c|}
\hline $\begin{array}{l}\text { Allergic triggers and } \\
\text { environmental controls have been } \\
\text { addressed }\end{array}$ & $\begin{array}{l}\text { Evaluation by an allergy/immunology specialist } \\
\text { might be considered to address these issues }\end{array}$ & 30,37 \\
\hline $\begin{array}{l}\text { Patient inhaler technique, } \\
\text { education, and adherence has } \\
\text { been maximized§ }\end{array}$ & $\begin{array}{l}\text { Guidelines consider patient education and compliance } \\
\text { key components of establishing disease control }\end{array}$ & 30,37 \\
\hline Serum IgE 30-700 IU/mL & $\begin{array}{l}\text { Required to help establish that the patient has allergic } \\
\text { asthma; dosing per the product labeling does not give } \\
\text { guidance for IgE concentrations outside of this range }\end{array}$ & 40 \\
\hline Body weight $30-150 \mathrm{~kg}$ & $\begin{array}{l}\text { Dosing per the product labeling does not give guidance } \\
\text { for patient weights outside of this range }\end{array}$ & 40 \\
\hline $\begin{array}{l}\text { Positive skin-prick testing or } \\
\text { RAST }\end{array}$ & $\begin{array}{l}\text { Per the product labeling; required to help establish } \\
\text { that the patient has allergic asthma }\end{array}$ & 40 \\
\hline \multicolumn{3}{|c|}{$\begin{array}{l}\text { * High-risk patients: those patients with a recent history (within the prior year) of frequent intubations, emergency room visits, overnight hospitalizations, intensive care unit } \\
\text { admissions for asthma exacerbations. }\end{array}$} \\
\hline \multicolumn{3}{|c|}{$\begin{array}{l}\text { † The severity of asthma may be classified by the frequency of symptoms and pulmonary function assessments prior to starting asthma therapy. However, since the criteria } \\
\text { presented here apply to treatment-experienced patients, patients may be considered to have severe persistent disease if they require therapy consistent with this degree of } \\
\text { disease despite not fulfilling the symptom frequency or pulmonary function requirements for severe persistent asthma. A low FEV (particularly } \leq 65 \%) \text { is more predictive } \\
\text { of response than higher FEVI values at treatment initiation. }\end{array}$} \\
\hline \multicolumn{3}{|c|}{$\begin{array}{l}\text { \# If a patient requires chronic corticosteroid maintenance therapy for symptom management (i.e., corticosteroid-dependent asthma), omalizumab may be considered to reduce } \\
\text { the exposure and long-term risks of this therapy even if such therapy provides adequate control. }\end{array}$} \\
\hline \multicolumn{3}{|c|}{$\begin{array}{l}\text { § If adherence and/or inhaler technique cannot be maintained despite documented adequate training and education, omalizumab may be considered if all other criteria are } \\
\text { fulfilled. }\end{array}$} \\
\hline
\end{tabular}

BDP $C F C=$ beclomethasone

7 monthly ED visits for treatment of asthma-related events. Hence, these and other authors recommend that its use be restricted for moderate-to-severe allergic asthma in patients who are suboptimally controlled and require regular use of intensive health care resources for management of exacerbations. ${ }^{6,52,61-63}$ Although other authors have questioned the validity of the outcome measures utilized by Oba and Salzman, even such critics agree that omalizumab use is cost prohibitive in most patients. Miller and Reeves calculated an incremental cost-effectiveness ratio of $\$ 88,837$ to prevent 1 unscheduled office visit for omalizumab versus placebo, $\$ 577,812$ to prevent 1 hospitalization, or $\$ 755,600$ to prevent 1 ED visit. ${ }^{64}$

\section{Conclusion}

Omalizumab is a subcutaneously administered monoclonal anti-IgE antibody that reduces free IgE concentrations and promotes down-regulation of IgE receptors on basophils. In patients with allergic asthma poorly controlled with inhaled steroids, omalizumab improves asthma symptom control and allows patients to be managed with lower inhaled steroid doses. Omalizumab has been well tolerated in clinical trials that have extended as long as 52 weeks. Almost half of patients experience injection-site reactions with omalizumab, and while these tend to decrease in frequency with subsequent dose administration, severe injection-site reactions occur in approximately 1 in 8 patients. Because omalizumab is much more expensive than standard asthma therapies, its use needs to be restricted to the most severe, poorly controlled allergic asthmatics who require frequent use of emergency care for exacerbations.

\section{DISCLOSURES}

No outside funding supported this study. The authors disclose no potential bias or conflict of interest relating to this article. Author Paul P. Belliveau served as 
principal author of the study. Study concept and design, data collection, and analysis and interpretation of data were contributed primarily by Belliveau, with input from author Monina R. Lahoz. Drafting of the manuscript was primarily the work of Belliveau, and its critical revision was the work of both authors.

\section{REFERENCES}

1. Weiss KB, Sullivan SD, Lyttle CS. Trends in the cost of illness for asthma in the United States, 1985-1994. J Allergy Clin Immunol. 2000;106:493-99.

2. Mellon M, Parasuraman B. Pediatric asthma: improving management to reduce cost of care. J Manag Care Pharm. 2004;10(2):130-41.

3. Meltzer EO, Szwarcberg J, Pill MW. Allergic rhinitis, asthma, and rhinosinusitis: diseases of the integrated airway. J Manag Care Pharm. 2004;10(4): 310-17.

4. National Asthma Education and Prevention Program. Expert panel report: guidelines for the diagnosis and management of asthma. Updated selected topics, 2002. J Allergy Clin Immunol. 2002;110(5 pt 2, suppl):S141-S219.

5. Garcia G, Adler M, Humbert M. Difficult asthma. Allergy. 2003;58:114-21.

6. Storms WW. Unmet needs in the treatment of allergic asthma: potential role of novel biologic therapies. J Manag Care Pharm. 2003;9(6):534-43.

7. Pearce N, Pekkanen J, Beasley R. How much asthma is really attributable to atopy? Thorax. 1999;54:268-72.

8. Burrows B, Martinez FD, Halonen M, Cline MG. Association of asthma with serum IgE levels and skin-test reactivity to allergens. N Engl J Med. 1989;320: 271-77.

9. Goldsby RA, Kindt TJ, Osborne BA, Kuby J, eds. Immunology. 5th ed. New York: W.H. Freeman and Company; 2003.

10. Hook WA, Zinsser FU, Berenstein EH, Siraganian RP. Monoclonal antibodies defining epitopes on human IgE. Mol Immunol. 1991;28:631-39.

11. Presta L, Shields R, O'Connell L, et al. The binding site on human immunoglobulin E for its high affinity receptor. J Biol Chem. 1994;269:26368-73.

12. Oettgen HC, Geha RS. IgE in asthma and atopy: cellular and molecular connections. J Clin Invest. 1999;104:829-35.

13. Broide DH. Molecular and cellular mechanisms of allergic disease. J Allergy Clin Immunol. 2001;108 (2 pt 1, suppl):S65-S71.

14. Kay AB. Allergy and allergic diseases. N Engl J Med. 2001;344:30-37.

15. Pearlman DS. Pathophysiology of the inflammatory response. J Allergy Clin Immunol. 1999;104 (4 pt 1, suppl):S132-S137.

16. Liu J, Lester P, Builder S, Shire SJ. Characterization of complex formation by humanized anti-IgE monoclonal antibody and monoclonal human IgE. Biochemistry. 1995;34:10474-82.

17. Chang TW. The pharmacological basis of anti-IgE therapy. Nat Biotechnol. 2000; 18:157-62.

18. Saban R, Haak-Frendscho M, Zine M, et al. Human FcERI-IgG and humanized anti-IgE monoclonal antibody MaEll block passive sensitization of human and rhesus monkey lung. J Allergy Clin Immunol. 1994;94:836-43.

19. Hook WA, Zinsser FU, Berenstein EH, Siraganian RP. Monoclonal antibodies defining epitopes on human IgE. Mol Immunol. 1991;28:631-39.

20. Malveaux FJ, Conroy MC, Adkinson NF, Lichtenstein LM. IgE receptors on human basophils. Relationship to serum IgE concentration. J Clin Invest. 1978;62:176-81.

21. MacGlashan D, McKenzie-White J, Chichester K, et al. In vitro regulation of FceRI expression on human basophils by IgE antibody. Blood. 1998;91: 1633-43.

22. MacGlashan DW, Bochner BS, Adelman DC, et al. Down-regulation of FcERI expression on human basophils during in vivo treatment of atopic patients with anti-IgE antibody. J Immunol. 1997;158:1438-45.

23. Soler M, Matz J, Townley R, et al. The anti-IgE antibody omalizumab reduces exacerbations and steroid requirement in allergic asthmatics.

Eur Respir J. 2001;18:254-61.
24. Busse W, Corren J, Lanier BQ, et al. Omalizumab, anti-IgE recombinant humanized monoclonal antibody, for the treatment of severe asthma. J Allergy Clin Immunol. 2001;108:184-90.

25. Holgate ST, Chuchalin A, Herbert J, et al. Efficacy and safety of a recombinant anti-immunologlobulin $\mathrm{E}$ antibody (omalizumab) in severe allergic asthma. Clin Exp Allergy. 2004;34:632-38.

26. Humbert M, Beasley R, Ayres J, et al. Benefits of omalizumab as add-on therapy in patients with severe persistent asthma who are inadequately controlled despite best available therapy (GINA 2002 step 4 treatment): INNOVATE. Allergy. 2005;60:309-16.

27. Buhl R, Soler M, Matz J, et al. Omalizumab provides long-term control in patients with moderate-to-severe asthma. Eur Respir J. 2002;20:73-78.

28. Lanier BQ, Corren J, Lumry W, Liu J, Fowler-Taylor A, Gupta N. Omalizumab is effective in the long-term control of severe allergic asthma. Ann Allergy Asthma Immunol. 2003;91:154-59.

29. Ayres JG, Higgins B, Chilvers ER, Ayre G, Blogg M, Fox H. Efficacy and tolerability of anti-immunoglobulin $E$ therapy with omalizumab in patients with poorly controlled (moderate-to-severe allergic asthma). Allergy. 2004; 59:701-08.

30. Expert panel report: Guidelines for the diagnosis and management of asthma. Update on selected topics, 2002. Bethesda, MD: National Institutes of Health, National Heart, Lung, and Blood Institute; June 2003; NIH Publication: 02-5074:1-129.

31. Buhl R. Omalizumab (Xolair) improves quality of life in adult patients with allergic asthma: a review. Respir Med. 2003;97:123-29.

32. Juniper EF, Guyatt GH, Epstein RS, Ferrie PJ, Jaeschke R, Hiller TK. Evaluation of impairment of health-related quality of life in asthma: development of a questionnaire for use in clinical trials. Thorax. 1992;47:76-83.

33. Juniper EF, Guyatt GH, Willan A, Griffith LE. Determining a minimal important change in a disease-specific quality of life questionnaire. J Clin Epidemiol. 1994;47:81-87.

34. Buhl R, Hanf G, Soler M, et al. The anti-IgE antibody omalizumab improves asthma-related quality of life in patients with allergic asthma. Eur Respir J. 2002;20:1088-94.

35. Finn A, Gross G, van Bavel J, et al. Omalizumab improves asthma-related quality of life in patients with severe allergic asthma. J Allergy Clin Immunol. 2003;111:278-84

36. Bousquet J, Cabrera P, Berkman N, et al. The effect of treatment with omalizumab, an anti-IgE antibody, on asthma exacerbations and emergency medical visits in patients with severe persistent asthma. Allergy. 2005;60:302-08,

37. Global Initiative for Asthma. Global strategy for asthma management and prevention. 2004. Available at: http://www.ginasthma.com. Accessed September 16, 2005.

38. Bousquet J, Wenzel S, Holgate S, Lumry W, Freeman P, Fox H. Predicting response to omalizumab, an anti-IgE antibody, in patients with allergic asthma. Chest. 2004;125:1378-86.

39. Holgate S, Bousquet J, Wenzel S, Fox H, Liu J, Castellsague J. Efficacy of omalizumab, an anti-immunoglobulin $\mathrm{E}$ antibody, in patients with allergic asthma at high risk of serious asthma-related morbidity and mortality. Curr Med Res Opin. 2001;17:233-40.

40. Omalizumab [(omalizumab for subcutaneous use), package insert]. South San Francisco, CA; Genentech, Inc.; June 2003.

41. Omalizumab: anti-IgE monoclonal antibody E25, E25, humanised antiIgE MAb, IgE 025, monoclonal antibody E25, Olizumab, Xolair, rhuMAbE25. BioDrugs. 2002;16:380-86.

42. Israel E, Cohn J, Meltzer E, McCarty J, Zheng B, Carroll A. Omalizumab does not induce thrombocytopenia in the treatment of asthma. Presented at: American Academy of Allergy, Asthma, \& Immunology 60th Annual Meeting; March 7-12, 2003; Denver, CO. Abstract 310. J Allergy Clin Immunol. 2003; 111(suppl):S367.

43. Rosenbaum JT, Dwyer JM. The role of IgE in the immune response to neoplasia: a review. Cancer. 1977;39:11-20. 
44. Winter WE, Hardt NS, Fuhrman S. Immunoglobulin E. Importance in parasitic infections and hypersensitivity responses. Arch Pathol Lab Med. 2000;124:1382-85.

45. Lethbridge-Cejky M, Vickeri J. Summary health statistics for U.S. adults: National Health Interview Survey, 2003. National Center for Health Statistics. Vital Health Stat 10. 2005;225:1-151.

46. Dey AN, Bloom B. Summary health statistics for U.S. children: National Health Interview Survey, 2003. National Center for Health Statistics. Vital Health Stat 10. 2005,223:1-78.

47. Centers for Disease Control and Prevention. Self-reported asthma among high school students, United States, 2003. MMWR. 2005;53(31):765-67.

48. The State of Asthma in America. Asthma in America Survey. A landmark survey. Executive Summary, Figure 20. GlaxoSmithKline. Available at: http://www.asthmainamerica.com/slides/slide20.htm. Accessed October 3, 2005.

49. The State of Asthma in America. Children and Asthma in America Survey. Executive Summary, Figure 7. GlaxoSmithKline. Available at: http://www.asthmainamerica.com/slides/children/07.html. Accessed October 3, 2005.

50. Cisternas MG, Blanc PD, Yen IH, et al. A comprehensive study of the direct and indirect costs of adult asthma. J Allergy Clin Immunol. 2003;111: 1212-18

51. National Center for Health Statistics. Asthma Prevalence, Health Care Use, and Mortality, 2002. U.S. Department of Health and Human Services, Centers for Disease Control and Prevention. Available at: http://www.cdc.gov/nchs/ products/pubs/pubd/hestats/asthma/asthma.htm. Accessed September 26, 2005.

52. Marshall GD, Sorkness CA. IgE-blocking therapy for difficult-to-treat asthma: a brief review. Manag Care. 2004;13:45-50.
53. Godard P, Chanez P, Siraudin L, et al. Costs of asthma are correlated with severity: a 1-yr. prospective study. Eur Respir J. 2002;19:61-67.

54. Serra-Batlles J, Plaza V, Morejon E, Comella A, Brugues J. Costs of asthma according to degree of severity. Eur Respir J. 1998;12:1322-26.

55. Smith DH, Malone DC, Lawson KA, et al. A national estimate of the economic costs of asthma. Am J Respir Crit Care Med. 1997;156:787-93.

56. Dolan CM, Fraher KE, Bleecker ER, et al. Design and baseline characteristics of the epidemiology and natural history of asthma: Outcomes and Treatment Regimens (TENOR) study: a large cohort of patients with severe or difficult-to-treat asthma. Ann Allergy Asthma Immunol. 2004;92:32-39.

57. Gergen PJ. Understanding the economic burden of asthma. J Allergy Clin Immunol. 2001;107 (5 pt 2, suppl):S445-S448.

58. Drug Topics Red Book, 2005 ed. Montvale, NJ: Medical Economics Company; 2005.

59. Omalizumab (Xolair): an anti-IgE antibody for asthma. Med Lett Drugs Ther. 2003;45:67-68.

60. Courtney AU, McCarter DF, Pollart SM. Childhood asthma: treatment update. Am Fam Physician. 2005;71:1959-68.

61. Oba Y, Salzman GA. Cost-effectiveness analysis of omalizumab in adults and adolescents with moderate-to-severe allergic asthma. J Allergy Clin Immunol. 2004;114:265-69.

62. Rambasek TE, Lang DM, Kavuru MS. Omalizumab: where does it fit into current asthma management? Cleve Clin J Med. 2004;71:251-61.

63. Bootman JL, Crown WH, Luskin AT. Clinical and economic effects of suboptimally controlled asthma. Manag Care Interface. 2004;17:31-36.

64. Miller TP, Reeves MJ. Lack of cost-effectiveness of omalizumab (letter). J Allergy Clin Immunol. 2005;115:429-30. 